NECROLÓGICA 



\section{Antoni M. Badia i Margarit (30 de mayo de 1920 -16 de noviembre de 2014)}

La marcha de la vida resulta inexorable, las edades de los seres humanos se suceden unas a otras, y ahora ya no está entre nosotros Antoni Badia. Sirvan las líneas presentes de recuerdo y testimonio.

Cabe en primer término situar a Antoni Badia en la secuencia de las generaciones intelectuales de la cultura española de los últimos cien años.

Quienes nacen de 1861 a 1875 dan lugar a la que se conoce como «generación del 98»: de Unamuno (*1864) a Antonio Machado (*1875); vienen luego los hombres del 14, nacidos entre 1876 y 1890: don José Ortega; Manuel Azaña; Manuel de Falla; Fernando de los Ríos; el doctor Marañón, etc.; no extraña que Juan [López] Marichal se entusiasmase antes estos nombres y esta generación.

La bien sabida «generación del 27» va de Pedro Salinas (*1891) a Manuel Altolaguirre (*1905). Hoy día está muy avalorada esta hornada, hay varias instituciones y fundaciones dedicadas a ella, pero ha de decirse una verdad: se trata de una generación egregia en cuanto a la lírica, pero por su peso histórico y político, por la obra intelectual — las Obras llamadas Completas del 98 y del 14 resultan extensísimas-, por el papel en la España contemporánea, etc., de todas estas generaciones las dos fundamentales son las del Noventayocho y la del Catorce. Nuestro distinguido amigo J. Neira ha postulado alguna vez que el centro de la vida intelectual española del primer tercio del Novecientos hay que referirlo al 27; nosotros creemos empero que tal centro es el referido a las mentadas generaciones del 98 y del 14.

No perteneció al Veintisiete el investigador y profesor Rafael Lapesa Melgar - aunque así lo creyese él mismo debido a sus vivencias juveniles y lo recogiese luego J. L. Girón-, sino que debe adscribirse a la generación española de 1936, la cual vino al mundo entre 1906 y 1920, y es una hornada de notorias figuras dedicadas a la indagación en ciencias humanas: Vicens - historiografía-; Lapesa (según queda dicho: de su fraterno don Amado [Alonso] le separaba el nacimiento respectivo en el tiempo que va entre 1896 y 1908); Juan Rof Carballo; Julio Caro Baroja; José Ferrater Mora; José Antonio Maravall; Vicente Llorens, Julián Marías; Juan Luis Alborg; etc. De los completamente jóvenes que vienen al mundo en estos años 06-20 está Badía, quien con su buena amistad con R. Lapesa, su dedicación a la diacronía y la dialectología, su esfuerzo personal por hacer una obra consistente, etc., se une característicamente a esta denominada «generación del 36».

Recogemos ahora de un «ensayo de autobiografía» que publicó Antoni Badia, algunos hechos, a saber:

1. Evoca nuestro autor a su padre en tanto «plenamente identificado con el movimiento catalanista». 
2. «En casa había millares de libros». Parece completamente verosímil que don Antonio heredase de su padre -independientemente de su gran talento natural personal, y de su voluntad férrea de estudioese catalanismo y la vocación que fomentaban los aludidos millares de libros. Se trataba - y así lo asumía personalmente- de «la construcción de un país y una cultura».

3. A partir de la «hecatombe» de 1939, «me sentí presa de un compromiso profundo [...]: la lengua y la cultura catalanas».

4. A los estudios universitarios llegó «con empuje, con vocación», empuje y vocación que ha mantenido hasta el final de su vida, una vida tan cumplida y lograda: una de sus últimas publicaciones extensas salió cuando se encontraba ya muy avanzado en años: en 1999.

5. Badía reconoce a A. Griera el haberse introducido en el campo de la romanística. No obstante, y sin maestros en Barcelona, «continuaba considerándome de formación personal».

6. Evoca el autor cómo «un día me presentaron a Rafael Lapesa». De esta manera — cabe añadir - el día 29 de noviembre de 1954 pudo exponer don Rafael en Barcelona lo que varias décadas más tarde iba a ser su Discurso de ingreso en la Academia de la Historia, Academia a la que él llevó a su antiguo profesor adjunto el Dr. Álvaro Galmés en disconformidad con el rechazo que a Galmés le hizo la de la Lengua (personalmente Lapesa me dio un testimonio acerca de tal rechazo que sería ahora indiscreto transcribir, pero que es muy ilustrativo y no renuncio a relatar algún día). Don Rafael y A. Galmés — créaseme - no eran respetados a veces y por algunos profesores, en el contexto madrileño que yo conozco desde 1970.

El día de su investidura como doctor honoris causa por mi Facultad, el propio Badía se reafirmó ante mi colega Julia Butinyà (a quien ha de agradecerse la iniciativa del acto) y se reafirmó ante mí mismo, en la amistad con el filólogo valenciano (Lapesa). De hecho y en la revista de la Fundación March Saber leer reseñó uno de los últimos volúmenes lapesistas.

7. En tanto «profesor auxiliar» de la Universidad de Barcelona, A. Badía empezó su docencia en «los cursos de «Gramática histórica española» y de «otras materias más o menos afines», entre ellas la de «Lingüística General». En cuanto a la última disciplina, recuérdense sus Panoramas de la lingüística en la edición en castellano de Vendryes y en el Espasa, también en Cuadernos para el diálogo, etc.

8. Obtenida la cátedra de esa «Gramática histórica española» a mitad de mayo de 1948 con casi 28 años, Antonio Badía, y «con la libertad que da una cátedra universitaria, yo orienté desde el primer momento - manifiesta - mi trabajo personal a español y a catalán, con creciente predominio de éste último». Durante 30 años tuvo el 
encargo asimismo de «Filología Catalana», y ya tras el franquismo, ocupó por concurso de traslado la cátedra paralela a la que venía desempeñando de «Gramática Histórica Catalana» (1977-1986).

Tenemos a la vista el «Programa de Gramática Histórica de la Lengua Española» que publicó Badía —en tanto «catedrático de la asignatura»- en Barcelona y en el mismo 1948, programa que verosímilmente transcribe el que había presentado al segundo ejercicio de sus oposiciones. Se trata de un trabajo concienzudo, consta de 100 lecciones, y se articula en varias partes sucesivas: la «gramática histórica» y los elementos constitutivos léxicos del español; la «Evolución del español», una Historia de la lengua en abreviatura; «Fonética», primero descriptiva y luego histórica; «Morfología»; «Sintaxis»; «Semántica». Hemos visto varios Programas de opositor, y el de Badía es el más detallado y mejor que conocemos -incluidos los que hubimos de hacer personalmente-.

Nuestro autor vemos que indica cómo una cátedra da «libertad», mas esto era más antes que ahora: en estos lustros últimos un catedrático está sujeto a controles que resultan desde luego razonables, pero que en la práctica resultan no siempre adecuados y equilibrados, pues de manera excluyente se pide que hay que tratar de determinados temas y no de otros; ha de publicarse en determinadas revistas y editoriales; ha de atenderse a determinadas orientaciones teóricas de escuela; etc.: todo lo que no se ajuste a esto resulta rechazado y en ocasiones maximalistamente; hay casos en que parece muy evidente que se desprecia lo que se desconoce (dos catedráticos de Crítica Literaria lo han hecho notar).

Los programas de radio, de televisión, etc., han acostumbrado a la sociedad española a que cualquiera juzgue a cualquiera, a que lo evalúe, lo discuta, pero no todos saben juzgar a todos: yo mismo hay varias materias filológicas o próximas a la filología - la Prehistoria, las denominadas lingüística clínica o lingüística matemática, la enseñanza del español como idioma extranjero, etc.- - que soy incapaz de juzgar. Entre nosotros existe algún caso de profesor que posee en el $B O E$ nombramiento para más de una área de conocimiento, mas pese a tal legalidad y legitimidad, se le censura la libertad constitucional de cátedra - la libertad sin más aludida por Badía - de escribir a la vez sobre las diferentes materias de tales áreas; hemos perdido libertad, hemos venido a menos, según denunció con lucidez y valentía Juan Goytisolo hace no muchos años.

9. En cuanto a la formación por sí mismo, Badía recuerda cómo «tenía asimiladas las publicaciones [...] de la escuela de Menéndez Pidal», y las de W. von Wartburg - en la $R F E$ le hizo una reseña que creemos memorable-. 
10. Nuestro profesor manifiesta haberse dedicado en estos lustros iniciales de cátedra a los asuntos proverbiales de la romanística de la primera mitad del siglo XX: fonética experimental, gramática histórica, dialectología, y toponimia.

11. Nuestro autor enuncia algo en lo que modestamente coincidimos con él: están bien los congresos, la docencia fuera de la Facultad en España o el extranjero, las conferencias, etc., pero «uno tiene que anteponer el trabajo personal —el motor del universitario-». Con su esfuerzo personal, Badía es uno de los ejemplos, de los paradigmas de conducta que recordamos y que cabe tomar como referencia.

12. La dialectología la entiende nuestro autor como lo que es, en tanto «complemento indispensable de la gramática histórica»: «el mundo en que me movía - evoca acerca de sus lustros iniciales de cátedra- era siempre el de la gramática histórica y disciplinas afines».

13. Antoni Badia escribe:

«Siempre me he sentido atraído por los estudiantes, me he lanzado a hacer mis cursos con entusiasmo, con verdadera pasión. [...] He sufrido enormemente al calificar exámenes (que me he leído varias veces en caso de duda). También me han interesado sus problemas, sus preocupaciones, sus vidas».

14. Nuestro autor subraya haber compartido «muchos puntos de vista» con Jaume Vicens Vives.

15. Desde hacia 1962, el investigador Badia inicia una nueva trayectoria temática, una segunda navegación: la dedicación a la sincronía y a las cuestiones de lengua y sociedad se hace ahora muy predominante, aunque en 1999 el autor vuelve a su temática filológica y escribe «Les Regles de esquivar vocables i la "qüestió de la llengua"».

Nosotros no vamos a referirnos ya en estas líneas a tal temática especializada.

Entre las publicaciones de asunto religioso de Antoni Badia hay una de 1968, de la que vamos a transcribir varios pasajes que den una idea del talante vital y humano del autor; las vimos en su día y acabamos de releerlas en la Biblioteca Nacional:

a) «El cristiano [...] se encuentra a cada momento ante multitud de situaciones de injusticia».

b) «Yo podré denunciar situaciones injustas [...], mejor dicho, no podré denunciarlas, tendré que denunciarlas».

c) «El compromiso del cristiano no tiene fin». 
d) «Donde haya una situación de malestar o de injusticia, allí hay algo que impide o retrasa o dificulta la realización del hombre, allí hay una situación todavía no salvada».

e) «El cristiano (que sea obispo, sacerdote o laico) es un descontento, un inquieto, un debelador de injusticia».

f) «El cristiano no puede estar nunca tranquilo. El compromiso no se acaba nunca, y nos hace la vida incómoda, dura [:...] La Cruz es dolorosa, hace sangre».

g) «Somos llamados a profetizar sobre la falta de realización del hombre, sobre las situaciones humanas que no han recibido - o que han olvidado- el mensaje salvífico de Jesucristo. El síntoma es fácil de reconocer: la injusticia».

$$
\text { *** }
$$

Una bibliografía de A. M. Badia hasta 1988 se encuentra en el número 81, de febrero de 1988, de Anthropos; en ese monográfico vid. —e. gr.—, la colaboración de Teresa Cabré.

$$
\text { *** }
$$

Para este modesto profesor que escribe ahora, Antoni M. Badia constituye un ejemplo como profesor, en tanto investigador, y como creyente cristiano progresista. 
